\title{
Testing for changes in light emissions from certified International Dark Sky Places
}

\author{
Emilee Hyde ${ }^{1}$, Sabine Frank ${ }^{2}$, John C. Barentine ${ }^{3,4}$, Helga Kuechly ${ }^{5}$, Christopher C.M. \\ $\mathrm{Kyba}^{5,6^{*}}$ \\ ${ }^{1}$ Nazareth College, Rochester, NY 14618, USA \\ ${ }^{2}$ UNESCO Biosphärenreservat Rhön, Landkreis Fulda, 36037 Fulda, Germany \\ ${ }^{3}$ International Dark-Sky Association, Tucson, AZ 85719, USA \\ ${ }^{4}$ Consortium for Dark Sky Studies, University of Utah, 375 S 1530 E, RM 235 ARCH, Salt \\ Lake City, Utah 84112, USA \\ ${ }^{5}$ GFZ German Research Centre for Geosciences, 14473 Potsdam, Germany \\ ${ }^{6}$ Leibniz Institute of Freshwater Ecology and Inland Fisheries (IGB), 12587, Germany
}

Received 15 May 2019, Accepted 24 June 2019

\begin{abstract}
The International Dark-Sky Places (IDSP) program of the International Dark-Sky Association is a voluntary certification in which communities commit via legislative changes to move towards more sustainable lighting that reduces light pollution. Over 115 IDSP have now been certified, so it is worthwhile to examine the extent to which this certification results in reduced light emissions. In this paper, we compare trends in upward light emission of 98 communities located in or near IDSP to those of 98 similarly populated communities further away from the IDSP, using a night lights observing satellite (the Visible Infrared Imaging Radiometer Suite Day-Night Band). The current dataset is not sufficient to distinguish the hypothesis that IDSP certification results in a lower rate of change in upward light emissions from the null hypothesis that IDSP certification has no impact. This result is with regard to upward light emissions only: it is possible that certification has resulted in decreases in night sky brightness that are not observable via downward looking satellite observations.
\end{abstract}

Keywords: International Dark Sky Places, remote sensing, remote sensing, VIIRS DNB

\section{Introduction}

Artificial light at night has grown tremendously over the last century and a half. Light emissions have grown in tandem with increases in gross domestic product and urban area, as well as due to improvements in lighting technology [1,2]. Technological improvements have not only made new forms of lighting possible, they have also made producing light less expensive, which in many cases leads to increasing consumption of light [3]. The overall brightening of the night has resulted in a number of negative consequences, including a diminished view of the night sky [4], impacts on human health [5], and impacts on illuminated ecosystems [6]. For example, circadian rhythms are often disrupted by artificial light [7], insect behavior is affected [8], with potential consequences for pollination [9] and population [10], and some trees bud earlier when exposed to light [11]. Despite the many known and suspected impacts of artificial light, discussion of efforts to reduce light pollution are sometimes met with resistance due to fears of increased crime or decreased road safety [12], regardless of whether these fears are justified $[13,14]$.

\footnotetext{
* Kyba CCM, Tel.: +49-331-288-28973

E-mail address: kyba@gfz-potsdam.de
} 
While light pollution continues to encroach on natural areas globally [15], there are some recent examples of communities and regions that have intentionally taken steps to minimize light pollution over large regions. The "International Dark Sky Places" (IDSP) program of the International Dark-Sky Association (IDA) [30] is designed to recognize areas that wish to reduce light pollution, and in most cases, preserve their existing natural and cultural resource of a "dark sky" $[16,17]$. In addition to reducing sky brightness, the program aims to increase the demand for sustainable lighting products, raise awareness of the value of good lighting practice among visitors, and to help develop the local or regional economy through astrotourism $[18,19]$. The aim is not to eliminate light emissions completely, but rather to follow best practices, including directing light more accurately, limiting total emissions, reducing blue light emissions, and lighting only at times that are needed [20,21]. In at least one case, these efforts were demonstrated to have resulted in a major improvement in night sky visibility [22].

It would be useful to know to what extent the Dark Sky Places program is associated with reductions in light pollution. Various approaches exist that aim to quantify artificial light impacts in and adjacent to protected places. $[23,24]$; however, such measurements entail both costly equipment and considerable effort. It is therefore interesting to ask whether or not changes in installed lighting may be revealed by nighttime satellite observations. While these do not provide equivalent information to ground-based observations (because of the different observation directions), effects such as reducing the illuminance of areas that are over-illuminated [25], better directing facade lighting [21], initiating lighting curfews or dimming schedules [26], and elimination of unnecessary lights [27] should be visible from space.

The Visible Infrared Imaging Radiometer Suite Day-Night Band (DNB) images nearly the entire Earth each night in a band from 500-900 nm [28]. From these observations, cloud- and moon-free composite images can be created [29]. Such datasets have in the past been used to examine national [1] and state-level [30] changes in lighting. In this study, we use the DNB images to investigate the effect of IDSP certification on the trend of light emissions in these areas. We formulated four specific hypotheses to test:

H1) Annual changes in light emissions from towns in or near IDSP are smaller (or more negative) than the changes in similar towns that are located further away from IDSP.

H2) Towns in or near IDSP experience an absolute reduction in light emissions during a time period overlapping the certification.

H3) The distribution of annual changes in light emissions for communities in or near IDSP is not the same as the distribution for communities further away from IDSP.

H4) The distribution of annual trends in light emission changes for the sample of communities tested is not normally distributed.

\section{Methods}

We examined lighting changes in selected regions that obtained certification as an "International Dark Sky Place" (IDSP) by the International Dark-Sky Association [31]. Two types of IDSP were considered, International Dark Sky Reserves (IDSR), and International Dark Sky Communities (IDSC). The IDSRs are large regions, and typically contain numerous small towns. The IDSCs are individual communities, and are often incorporated municipalities. In both cases, certification requires the communities to voluntarily commit to transition to sustainable lighting practice. The certification requires a clear buy-in from the local community, including the political and business communities. During and following certification, all public street and area lighting must be converted to have no direct upward emissions (i.e. ULR=0\%) and restricting CCT to $3000 \mathrm{~K}$ or below within 1013 years. Private, industrial, and commercial lighting is encouraged, but not required, to also convert; these conversions are expected to often be undergone as part of replacement on failure. In addition to changing lighting, the IDSP program requires applicants to engage both residents and visitors with outreach to draw public attention to local efforts aimed at reducing light pollution. The goal of this outreach is to build support for public policies intended to codify lighting changes into law, and therefore improve compliance rates with those policies, especially among private property owners.

We set out to evaluate the efficacy of this approach to light pollution control by asking whether changes in upward light emissions in these protected places, as detected through remote sensing methods, were smaller relative to nearby "control" locations that are not under the same protections. We selected a set of International Dark Sky Reserves and Communities that obtained certification during 2014 or 2015. This timeframe ensures that satellite data from DNB was available both before and after the certification. Four IDSRs and eight IDSCs fit these criteria, and are the focus of this study (Table 1, Figure 1). Other types of IDSPs certified during this time 
period (Parks and Sanctuaries) do not typically have settlements within the area, and were therefore not considered in this analysis.

Table 1. International Dark Sky Places included in the analysis. The asterisk $(*)$ indicates that Silver Cliff and Westcliffe are designated as a single IDSC, but were analyzed as two separate areas.

\begin{tabular}{|c|c|c|c|}
\hline IDSP Type & IDSP Name & Year of certification & Size $\left(\mathrm{km}^{2}\right)$ \\
\hline Reserve & Kerry & 2014 & 700 \\
\hline \multirow[t]{2}{*}{ Reserve } & Rhön & 2014 & 1720 \\
\hline & Snowdonia National & & \\
\hline \multirow[t]{2}{*}{ Reserve } & Park & 2015 & 2132 \\
\hline & Westhavelland Nature & & \\
\hline Reserve & Park & 2014 & 748 \\
\hline Community (suburban) & Beverly Shores & 2014 & 15 \\
\hline Community (suburban) & Bon Accord & 2015 & 2.1 \\
\hline Community (exurban) & Dripping Springs & 2014 & 303 \\
\hline \multirow[t]{2}{*}{ Community (exurban) } & Horseshoe Bay & 2015 & 30 \\
\hline & Kaibab Paiute Indian & & \\
\hline Community (rural) & Reservation & 2015 & 489 \\
\hline Community (rural) & Sedona & 2014 & 50 \\
\hline Community (rural) & Silver Cliff \& Westcliffe & 2015 & $43 *$ \\
\hline
\end{tabular}
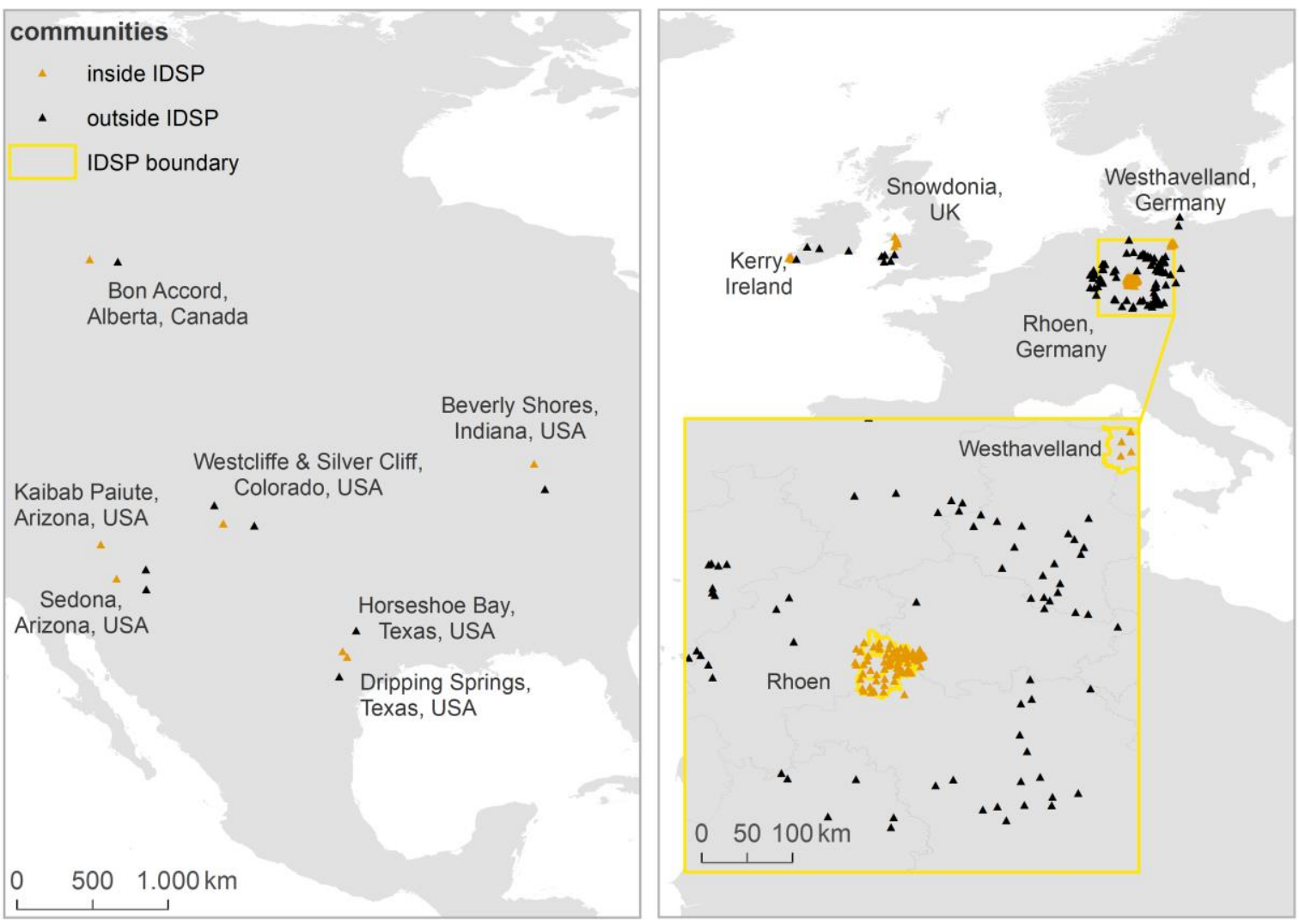

Figure 1: Map showing the locations of the examined communities. Communities inside of IDSP are indicated with an orange triangle, partner communities with a black triangle. The boundaries of IDSR Rhön and Westhavelland are shown in the inset. The background country maps are based on GADM version 2.6 (2018), https://gadm.org/download_world.html. 
The analysis made use of data collected from the Visible Infrared Imaging Radiometer Suite Day/Night Band (DNB) on the Suomi NPP satellite (https://www.ngdc.noaa.gov/eog/viirs/download_dnb_composites.html). The sensor observes radiance in $\mathrm{nW} / \mathrm{cm}^{2} \mathrm{sr}$ in a band from approximately 500-900 $\mathrm{nm}$ [29, 32]. At the time of the analysis, data from April 2012 to October 2018 was available. The data consist of "monthly composites" produced by the Earth Observation Group (EOG) of the National Oceanic and Atmospheric Administration (NOAA) [29]. While the intrinsic resolution of DNB is about 750 meters, these composites contain data projected onto a map with a 15 arcsecond grid. Each location in this study was imaged 1-2 times per night, and the EOG used nights with clear conditions, without twilight or moon illumination, and with no stray light falling on the satellite [29] to assign a single value to each location. This procedure reduces the intrinsic variability of the data, but monthly variations at typically the $15-20 \%$ level remain for single pixels [33]. These variations are reduced when a larger area is considered [33].

We used the "Radiance Light Trends" web application (henceforth "the app") to select regions, access the DNB data, and measure trends over time (https://lighttrends.lightpollutionmap.info). Coordinates and maps of the IDSP were used to identify villages and towns within the IDSP (in the case of IDSC, only a single community is considered). For each town, a polygon was drawn in the app that encompassed the settled area of the community (Figure 2). This was accomplished using both aerial imagery and EOG's annual DNB composite for 2016 [29]. The coordinates of the polygonal points, center of the polygon, and area of the DNB pixels contained within the polygon were recorded, and are available as a supplementary dataset [34]. For each community within an IDSP, a "comparison town" with a similar population (up to $20 \%$ difference based on populations reported in Wikipedia) was selected within 100 to $300 \mathrm{~km}$ away, and inside of the same country. The same procedure of drawing polygons was followed for the comparison towns, and these are also available in the supplementary dataset [34].

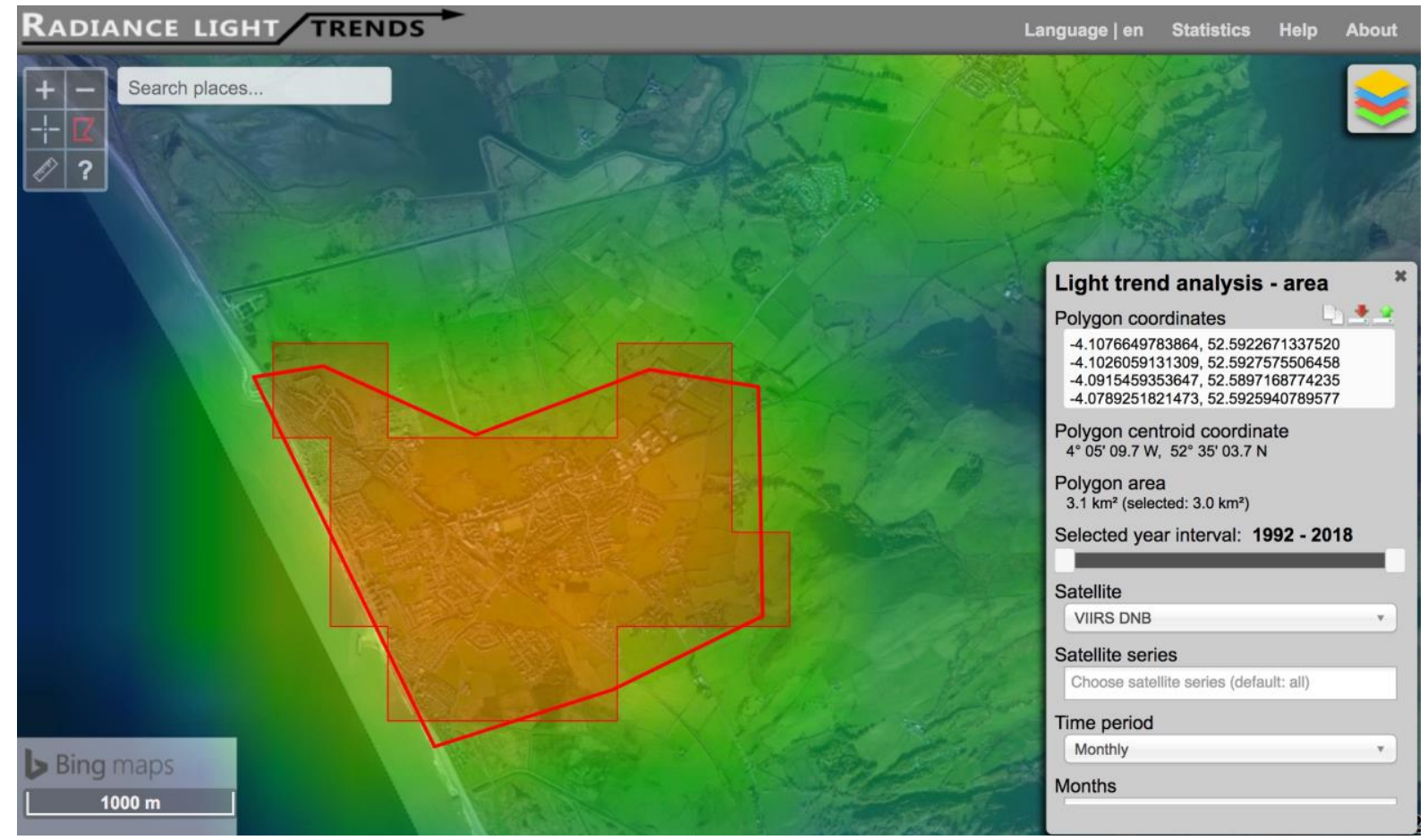

Figure 2: Radiance Light Trends screenshot showing the area analyzed near Tywyn, Wales, UK The green glow is the night lights data, set partially transparent to allow the aerial imagery to be shown below. The red polygon was drawn to encompass the community, and the red shaded areas are the DNB pixels selected for the analysis of Tywyn. Bing screen shot reprinted with permission from Microsoft Corporation.

For three of the IDSR, four or five towns were selected within the reserve boundaries. In IDSR Rhön, every town was analyzed, as we had additional information regarding the status of lighting legislation for each town. This allows us to compare lighting trends in towns with legislation enacted compared to those without. However, this also means the Rhön includes three times more communities than the rest of the IDSP examined, and so dominates in terms of the total number of communities examined.

A major source of variation in the monthly DNB composites is due to seasonal changes, particularly snow cover [2,33]. For this reason, for each IDSP we examined radiance trends for nearby areas that were not part of the main analysis, in order to select a set of months that experienced relatively little variation. In general, at the 
northern latitudes where the study's IDSR are located, the winter months of December to March are problematic, because of occasional snow cover that dramatically increases the radiance observed by DNB [2]. From April to August, and in the case of northern Germany September, the satellite is illuminated by stray light, and therefore does not produce data used in this analysis. In order to make the data as equivalent as possible, the same months were used for all towns within IDSR: September, October, and November. The IDSC were located within the United States and Canada. Due to larger range in climates compared to the IDSR, different months were selected for each community based on the same process of determining outliers for nearby areas mentioned above. The number of months analyzed therefore varied for the IDSC, especially because the lower latitude locations were less affected by stray light on the satellite during the summer months.

After a polygon was drawn in the web app, the app graphed the observed DNB data, and performed an exponential fit to the data. The app reported the fit annual change as a percentage, and this was recorded, along with the value of the trendline at the start of 2015. The data were then grouped into categories for further analysis (Table 2). For example, we compared towns in the Rhön which had already passed legislation regarding lighting to those in the Rhön which had not, in both cases with a set of comparison towns which were not located within Rhön, but rather within 100-300 km distance.

Table 2. Groupings used for the analysis.

\begin{tabular}{lccc} 
IDSP Type & Grouping & Total \# communities & Total \# comparison towns \\
\hline Reserve & $\begin{array}{c}\text { Kerry, Snowdonia, } \\
\text { Westhavelland }\end{array}$ & 14 & 14 \\
\hline Reserve & All of Rhön & 76 & 76 \\
\hline Reserve & Rhön legislation & 39 & 39 \\
\hline Reserve & Rhön no legislation & 37 & 37 \\
\hline Community & All IDSC & 8 & 8 \\
\hline Combined & All towns in IDSR and IDSC & 98 & 98 \\
\hline
\end{tabular}

For each grouping, the data for the IDSP communities and comparison towns was stored in a spreadsheet (available in the supplementary dataset [34]). Using the statistical software R, we calculated the mean, median, and standard deviation of the fit annual change in lighting emission for each group. We also tested for a lack of difference between the IDSP towns to the comparison towns using the Kolmogorov-Smirnov test, the unpaired Student's $t$ test, and the Unpaired Two-Samples Wilcox Test. The multiple tests were planned in advance, because before we acquired the data we did not expect the rate of change data would be normally distributed.

It is critical to note that the fit changes for each town are not truly independent observations, because the towns are located fairly close to each other, and experience similar seasonal variations (see [33]). For example, if the radiance observed for a town in IDSR Westhavelland fluctuates upward in one October, it must be expected that the neighboring towns will experience a similar upward fluctuation. Since the observations are correlated to an unknown degree, the $p$-values reported from standard statistical tests are not valid (reported $p$ will be smaller than would be expected for truly independent observations). Although the tests used cannot be trusted to positively identify a difference between the two sets of towns, the observation of a large $p$ value would strongly suggest that there is not a significant difference between the towns.

\section{Results}

The impact of certification on trends in light emission during the period from April 2012 to October 2018 for towns near or in an IDSP that was certified in 2014 or 2015 is ambiguous. The distribution of measured rates of change for towns in or near IDSP and partner towns is broadly similar when all communities are compared together, and the standard deviation (SD) of the data is considerably larger than the mean change (Figure 3). The comparison of all communities analyzed may be slightly misleading, however, as communities near IDSR Rhön made up 76 of the 98 total communities studied, and the trends for communities in IDSR Rhön may be different from the other areas studied (Tables 2 and 3). Similarly, while the mean annual increases in light emissions for all IDSP combined was larger (3.1\%, SD 6.0\%) than for the partner towns $(2.9 \%$, SD 5.0\%), this result is entirely due to the communities in the Rhön, where communities inside or near the IDSR experienced growth in 
lighting emissions of $4.3 \%$ (SD 6.0\%) per year, while partner communities light emissions grew at only $3.2 \%$ (SD 4.9\%) per year. Communities in the Rhön that had approved lighting regulations had smaller annual growth (3.8\%, SD 6.6\%) than those that had not yet approved regulations (4.8\%, SD 5.3\%). In all of the other IDSP considered, changes in lighting were smaller (or more negative) than for the partner communities, which is consistent with hypothesis 1.

IDSP Towns

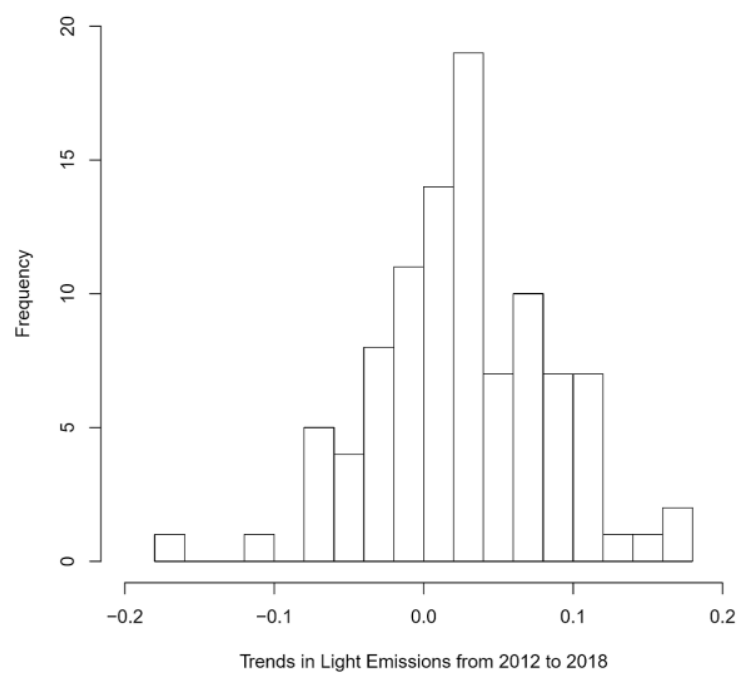

Comparison Towns for IDSP

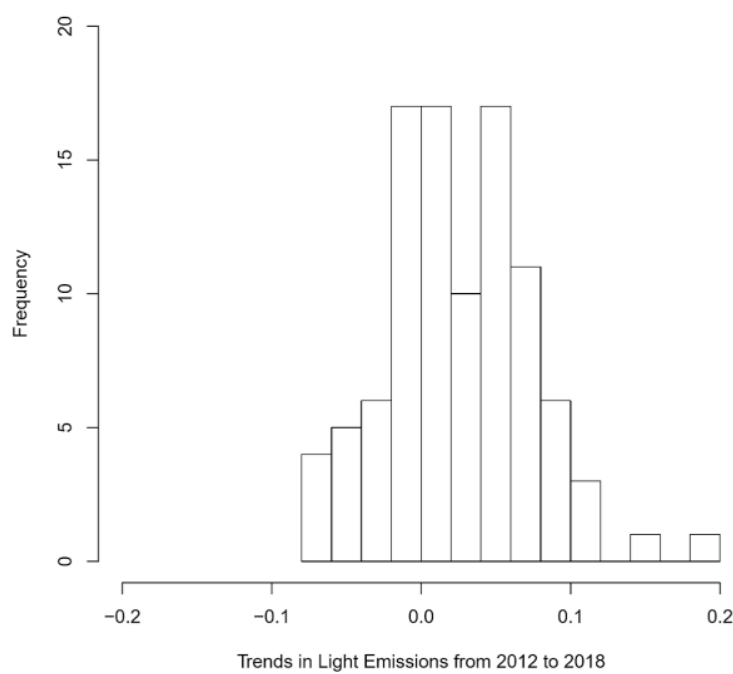

Figure 3: Histogram of fractional annual change in light emissions for all towns in or near IDSP (left) and all partner towns (right). A value of 0.1 indicates an increase of $10 \%$ per year, -0.1 indicates a decrease of $10 \%$ per year.

Table 3. Summary of light trends results. The average changes during the period 2012-2018 are shown, along with the standard deviation. The four International Dark Sky Reserves are shown separately, and the "combined" group is the combination of Westhavelland, Snowdonia, and Kerry. The "total" group includes towns from all International Dark Sky Places combined. For Rhön, "approved" indicates that the community had approved of legislation restricting light list.

\begin{tabular}{|c|c|c|c|c|c|}
\hline Name & Class & $\begin{array}{l}\text { Number } \\
\text { of towns }\end{array}$ & $\begin{array}{c}\text { Median annual } \\
\text { change (\%) }\end{array}$ & $\begin{array}{c}\text { Mean annual } \\
\text { change (\%) }\end{array}$ & $\begin{array}{c}\text { Standard } \\
\text { deviation (\%) }\end{array}$ \\
\hline \multirow{4}{*}{ Rhön } & In reserve & 76 & +3.8 & +4.3 & 6.0 \\
\hline & Outside & 76 & +3.1 & +3.2 & 4.9 \\
\hline & Approved & 39 & +3.7 & +3.8 & 6.6 \\
\hline & Not approved & 37 & +4.2 & +4.8 & 5.3 \\
\hline \multirow{2}{*}{ Kerry } & In reserve & 4 & +2.3 & +2.5 & 3.9 \\
\hline & Outside & 4 & +3.2 & +2.8 & 3.3 \\
\hline \multirow{2}{*}{ Snowdonia } & In reserve & 5 & -7.0 & -4.8 & 3.5 \\
\hline & Outside & 5 & +0.7 & -1.2 & 3.5 \\
\hline \multirow{2}{*}{ Westhavelland } & In reserve & 5 & -0.5 & -0.6 & 2.3 \\
\hline & Outside & 5 & +7.6 & +7.0 & 3.5 \\
\hline \multirow{2}{*}{ IDSR combined } & In reserve & 14 & -1.2 & -1.2 & 4.3 \\
\hline & Outside & 14 & +1.7 & +2.9 & 4.8 \\
\hline \multirow{2}{*}{ Communities } & IDSC & 8 & -0.3 & -0.6 & 2.2 \\
\hline & Not IDSC & 8 & -0.2 & +0.8 & 5.4 \\
\hline \multirow{2}{*}{ Total } & IDSP & 98 & +2.9 & +3.1 & 6.0 \\
\hline & Not IDSP & 98 & +2.6 & +2.9 & 5.0 \\
\hline
\end{tabular}


The second hypothesis, that towns near an IDSR would have absolute declines in light emissions, was observed in the mean and median changes for the IDSC and for IDSRs Westhavelland and Snowdonia, but not for IDSRs Kerry or Rhön. In both Snowdonia and Westhavelland, 4 out of the 5 communities examined had negative trends, while all 5 of the partner communities in both cases had positive trends (see Supplement [34]). On the whole, it does not appear that IDSP certification leads to large decreases in light emissions, at least not on the 6 year timescale of this study.

Since we did not expect the distribution of changes in light emissions to be normally distributed, we tested the similarity of the distributions using the Kolmogorov-Smirnov (KS) test. The calculation was performed in R, using the routine ks.test. Comparing all 98 IDSP communities to all 98 partner communities, the expected probability of observing a smaller difference in the KS test was $69 \%$. This suggests that the observations of lighting change in the IDSP and partner communities are drawn from a similar, or the same, underlying distribution as each other. For the IDSC and their partner communities, the KS probability was $96 \%$, while for the IDSR excluding Rhön it was $15 \%$. These results do not support hypothesis 3, and mean that we cannot definitely conclude whether the observed differences are due to statistical fluctuations or to real differences in annual changes in light emissions. As an additional check, Student t-tests were also used to compare the difference in mean lighting change between the IDSP communities and their partners (hypothesis 1 ). The $p$-value for all data taken together was 0.85 , and the only case in which the $p$-value was relatively small was for that of IDSR excluding Rhön, where it was 0.025 .

The final hypothesis (H4) was that the distributions would not be normally distributed. The reason we expected this is that the DNB data is correlated at spatial scales of a few hundred $\mathrm{km}$, most likely due to large scale weather [33]. Since the data points are not independent, we therefore expected the distributions of lighting change to differ from a normal distribution. The distribution shape was examined using the Shapiro-Wilk's test (shapiro.test in R) for the complete set of IDSP, and for the complete set of comparison towns. We found that contrary to our expectations, both distributions were not significantly different from the normal distribution $(\mathrm{W}=0.97, p=0.051$ for IDSP and $\mathrm{W}=0.98, p=0.19$ for partner towns).

\section{Discussion and Conclusion}

The mean and median rates of change in upward light emissions at night observed by satellite from 3 of the 4 International Dark Sky Reserves was smaller than for comparison towns, and this was also the case in the International Dark Sky Communities. In the fourth IDSR, the rate of change was smaller in towns that had approved legislation limiting light than in those that had not, but the rate of change of towns in the reserve overall was larger than that for the comparison towns. Taken together, this data is inconclusive: it is consistent both with the hypothesis that achieving IDSP status has an effect on lighting trends, as well as with the hypothesis that achieving the status has no effect.

The possibility of remotely sensing the impacts of lighting policy remains tantalizing. There are currently 117 International Dark Sky Places worldwide [35], which means that in the near future, it would be possible to greatly expand upon this study in terms of the number of regions examined. In addition, as time goes on and more observations are made, the estimate of lighting trends in each region will be more accurate. Nevertheless, this effort will present several challenges.

The first challenge, which has already been discussed, is the problem of dealing with the spatial correlation of temporal variation in the satellite datasets [33], as well as the fact that the communities are embedded in a specific social context (e.g. a single country's laws, norms, economic situation, etc.). Simply put: observations from multiple nearby towns cannot be considered statistically independent observations, and therefore standard statistical tests cannot be used to determine the extent to which the data diverge from the null hypothesis (that IDSP certification has no effect). Even if the towns are grouped together into single data points for each dark sky place, the fact remains that the location of the dark sky places themselves are spatially correlated (e.g. many are located in the American West).

A second challenge is that the satellites do not observe all light emissions, but rather light emitted upwards at relatively large angles. If a community replaces lamps that have considerable emission above the horizon and at glare angles with lamps that have more sharply cut off distributions, the total light emission could be cut considerably while the amount of light reflected from the ground remains nearly constant. The satellite observations can therefore be expected to provide more information about the rate at which new lights are added than in the total light emission. 
A third challenge is related to the worldwide conversion of existing lamps to white LEDs. The VIIRS DNB sensor has a spectral response from roughly $500-900 \mathrm{~nm}$. This means that the radiometer is able to observe the IR emission from high pressure sodium (HPS) lamps, but cannot observe blue emissions (400-500 nm). For this reason, a spectral conversion from HPS to white LED that left all else identical would lead to the satellite reporting typically a $30 \%$ decrease in emissions, depending on the exact LED and HPS spectra $[1,36]$. Until multispectral night lights satellite radiometers are developed, this problem will remain. If IDSP and comparison communities chose equivalent LED lamps, this might not matter, but in practice it is to be expected that IDSP will choose lamps with reduced blue emissions, exacerbating this problem.

Finally, we wish to stress one final time that satellite datasets measure upward emission, not sky brightness. Understanding changes in night sky radiance in the IDSP will require ground based observations [24]. The satellite datasets provide useful complementary information, particularly in regards to the installation of new lighting or elimination of unnecessary lighting. However, the different observation directions mean that satellite datasets can most likely never eliminate the need for ground observations to understand changes in night sky brightness.

\section{Acknowledgements}

We thank Adam Dalton for providing critical feedback on an early draft of our manuscript. EH acknowledges the support of Studienforum Berlin e.V.. CCMK acknowledges the funding received through the European Union's Horizon 2020 research and innovation programme ERA-PLANET, grant agreement no. 689443, via the GEOEssential project, and funding from the Helmholtz Association Initiative and Networking Fund under grant ERC-RA-0031. Image and Data processing by NOAA's National Geophysical Data Center. We salute the communities and parks examined in this project for their work in achieving IDSP certification, and for their commitment towards the principle of sustainable lighting.

\section{References}

[1] Kyba, C. C., Kuester, T., De Miguel, A. S., Baugh, K., Jechow, A., Hölker, F., ... \& Guanter, L. (2017). Art ificially lit surface of Earth at night increasing in radiance and extent. Science advances, 3(11), e1701528.

[2] Levin, N., \& Zhang, Q. (2017). A global analysis of factors controlling VIIRS nighttime light levels from d ensely populated areas. Remote sensing of environment, 190, 366-382.

[3] Tsao, J. Y., Saunders, H. D., Creighton, J. R., Coltrin, M. E., \& Simmons, J. A. (2010). Solid-state lighting: an energy-economics perspective. Journal of Physics D: Applied Physics, 43(35), 354001.

[4] Falchi, F., Cinzano, P., Duriscoe, D., Kyba, C. C., Elvidge, C. D., Baugh, K., ... \& Furgoni, R. (2016). The new world atlas of artificial night sky brightness. Science advances, 2(6), e1600377.

[5] Lunn, R. M., Blask, D. E., Coogan, A. N., Figueiro, M. G., Gorman, M. R., Hall, J. E., ... \& Stevens, R. G. (2017). Health consequences of electric lighting practices in the modern world: a report on the National To xicology Program's workshop on shift work at night, artificial light at night, and circadian disruption. Scien ce of The Total Environment, 607, 1073-1084.

[6] Rich, C., \& Longcore, T. (Eds.). (2013). Ecological consequences of artificial night lighting. Island Press.

[7] Ouyang, J. Q., de Jong, M., van Grunsven, R. H., Matson, K. D., Haussmann, M. F., Meerlo, P., ... \& Spoel stra, K. (2017). Restless roosts: Light pollution affects behavior, sleep, and physiology in a free-living song bird. Global change biology, 23(11), 4987-4994.

[8] Owens, A. C., \& Lewis, S. M. (2018). The impact of artificial light at night on nocturnal insects: A review and synthesis. Ecology and evolution, 8(22), 11337-11358.

[9] Knop, E., Zoller, L., Ryser, R., Gerpe, C., Hörler, M., \& Fontaine, C. (2017). Artificial light at night as a ne w threat to pollination. Nature, 548(7666), 206.

[10] Grubisic, M., Van Grunsven, R. H. A., Kyba, C. C. M., Manfrin, A., \& Hölker, F. (2018). Insect declines a nd agroecosystems: does light pollution matter? Annals of applied biology, 173(2), 180-189.

[11] Ffrench-Constant, R. H., Somers-Yeates, R., Bennie, J., Economou, T., Hodgson, D., Spalding, A., \& McG regor, P. K. (2016). Light pollution is associated with earlier tree budburst across the United Kingdom. Pro ceedings of the Royal Society B: Biological Sciences, 283(1833), 20160813.

[12] Green, J., Perkins, C., Steinbach, R., \& Edwards, P. (2015). Reduced street lighting at night and health: a ra pid appraisal of public views in England and Wales. Health \& place, 34, 171-180.

[13] Steinbach, R., Perkins, C., Tompson, L., Johnson, S., Armstrong, B., Green, J., ... \& Edwards, P. (2015). Th e effect of reduced street lighting on road casualties and crime in England and Wales: controlled interrupted 
time series analysis. J Epidemiol Community Health, 69(11), 1118-1124.

[14] Marchant, P. (2017). Why lighting claims might well be wrong. International Journal of Sustainable Lightin g, 19(1), 69-74.

[15] Gaston, K. J., Duffy, J. P., \& Bennie, J. (2015). Quantifying the erosion of natural darkness in the global pr otected area system. Conservation Biology, 29(4), 1132-1141.

[16] Gallaway, T. (2010). On light pollution, passive pleasures, and the instrumental value of beauty. Journal of Economic Issues, 44(1), 71-88.

[17] Stone, T. (2018). The value of darkness: A moral framework for urban nighttime lighting. Science and engi neering ethics, 24(2), 607-628.

[18] Collison, F. M., \& Poe, K. (2013). “Astronomical tourism”: The astronomy and dark sky program at Bryce Canyon National park. Tourism Management Perspectives, 7, 1-15.

[19] Labuda, M., Koch, R., \& Nagyová, A. (2015). " Dark Sky Parks" as measure to support nature tourism in la rge protection areas-case study in the Nature Park" Nossentiner/Schwinzer Heide". Naturschutz und Landsc haftsplanung, 47(12), 380-388.

[20] Falchi, F., Cinzano, P., Elvidge, C. D., Keith, D. M., \& Haim, A. (2011). Limiting the impact of light pollut ion on human health, environment and stellar visibility. Journal of environmental management, 92(10), 271 4-2722.

[21] Kyba, C. C., Mohar, A., Pintar, G., \& Stare, J. (2018). Reducing the environmental footprint of church light ing: Matching facade shape and lowering luminance with the EcoSky LED. International Journal of Sustain able Lighting, 20(1), 1-1.

[22] Aubé, M., \& Roby, J. (2014). Sky brightness levels before and after the creation of the first International D ark Sky Reserve, Mont-Mégantic Observatory, Québec, Canada. Journal of Quantitative Spectroscopy and Radiative Transfer, 139, 52-63.

[23] Hänel, A., Posch, T., Ribas, S. J., Aubé, M., Duriscoe, D., Jechow, A., ... \& Spoelstra, H. (2018). Measurin $\mathrm{g}$ night sky brightness: methods and challenges. Journal of Quantitative Spectroscopy and Radiative Transf er, 205, 278-290.

[24] Barentine, J. C. (2019). Methods for Assessment and Monitoring of Light Pollution around Ecologically Se nsitive Sites. Journal of Imaging, 5(5), 54.

[25] Narendran, N., Freyssinier, J. P., \& Zhu, Y. (2016). Energy and user acceptability benefits of improved illu minance uniformity in parking lot illumination. Lighting Research \& Technology, 48(7), 789-809.

[26] Ngarambe, J., \& Kim, G. (2018). Sustainable Lighting Policies: The Contribution of Advertisement and De corative Lighting to Local Light Pollution in Seoul, South Korea. Sustainability, 10(4), 1007.

[27] Arnold, G., Mellinger, D., Markowitz, P., Burke, M., \& Lahar, D. (2012). A Win-Win-Win for Municipal S treet Lighting: Converting Two-Thirds of Vermont's Street Lights to LED by 2014. 2012 ACEEE Summer Study on Energy Efficiency in Buildings.

[28] Miller, S., Straka, W., Mills, S., Elvidge, C., Lee, T., Solbrig, J., ... \& Weiss, S. (2013). Illuminating the cap abilities of the suomi national polar-orbiting partnership (NPP) visible infrared imaging radiometer suite (V IIRS) day/night band. Remote Sensing, 5(12), 6717-6766.

[29] Elvidge, C. D., Baugh, K., Zhizhin, M., Hsu, F. C., \& Ghosh, T. (2017). VIIRS night-time lights. Internatio nal Journal of Remote Sensing, 38(21), 5860-5879.

[30] Kyba, C. C., Kuester, T., \& Kuechly, H. U. (2017). Changes in outdoor lighting in Germany from 2012-201 6. International Journal of Sustainable Lighting, 19(2), 112-112.

[31] International Dark-Sky Association International Dark Sky Places Program. https://www.darksky.org/ ourwork/conservation/idsp/, accessed on 2019-05-13.

[32] Kyba, C., Garz, S., Kuechly, H., de Miguel, A., Zamorano, J., Fischer, J., \& Hölker, F. (2015). High-resolut ion imagery of earth at night: New sources, opportunities and challenges. Remote sensing, 7(1), 1-23.

[33] Coesfeld, J., Anderson, S., Baugh, K., Elvidge, C., Schernthanner, H., \& Kyba, C. (2018). Variation of indi vidual location radiance in VIIRS DNB monthly composite images. Remote Sensing, 10(12), 1964.

[34] Hyde, E., Kyba, C. (2019). Analysis boundaries and lighting trends (2012-2018) for selected International Dark Sky Places. GFZ Data Services, DOI:10.5880/GFZ.1.4.2019.002

[35] International Dark-Sky Association (2019, May 6). International Dark Sky Places. Retrieved from https://w ww.darksky.org/our-work/conservation/idsp/

[36] de Miguel, A. S., Kyba, C. C., Aubé, M., Zamorano, J., Cardiel, N., Tapia, C., ... \& Gaston, K. J. (2019). C olour remote sensing of the impact of artificial light at night (I): The potential of the International Space Sta tion and other DSLR-based platforms. Remote Sensing of Environment, 224, 92-103. 